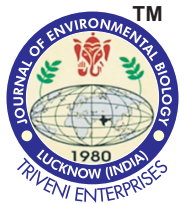

DOI : http://doi.org/10.22438/jeb/39/6/MRN-718

\title{
Characterization, evaluation and multivariate analysis of sunflower germplasm under semi-arid environments of three locations in two sunflower growing states in India
}

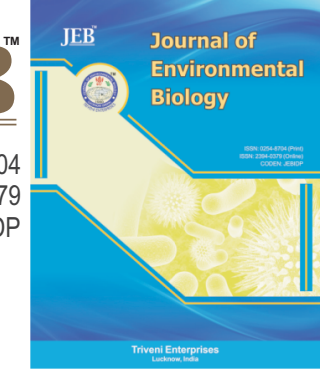

Authors Info

M.Y. Dudhe ${ }^{1 *}$, A.B. Rajguru, K.D. Bhoite ${ }^{3}$, S.M. Kadam ${ }^{3}$, A.R.G. Ranganatha', M. Sujatha' and A.V. Reddy

Crop Improvement Section, ICAR-Indian Institute of Oilseeds Research (IIOR), Rajendranangar,

Hyderabad-500 030, India

${ }^{2}$ Zonal Agriculture Research Station (ZARS), Solapur-413 002 India

${ }^{3}$ Agricultural Research Station (ARS), Savalvihir-423 109, India

*Corresponding Author Email : mangesh.dudhe@icar.gov.in

Key words

Biplot

Gene pool

Seed yield

Semi-arid environment

Sunflower

Publication Info

Paper received: 12.08 .2017

Revised received : 11.01 .2018

Re-revised received : 19.02 .2018

Accepted : 26.02 .2018

\section{Abstract}

Aim : The present study aimed at identifying high yielding genotypes through principal component analysis and cluster analysis by utilizing multilocation data generated by growing 32 germplasm accessions under semi-arid environments of Telangana and Maharashtra states.

Methodology : The evaluation trial was conducted in two Indian states Telangana (Hyderabad) and Maharashtra (Solapur and Savalvihir). R software 3.1.3 package was used to determine the major descriptive statistics, cluster analysis, principal component analysis (PCA) and correlations among the yield contributing traits.

Results : Wide range of genetic variation for seed yield and its components were recorded in the accessions studied. Principal component analysis disclosed that the first four components with eigen values greater than 0.43 contributed about $93.3 \%$ of total variability in the studied germplasm involving all the seven characters. The genotypes analysed were grouped into eleven clusters, out of which cluster IX was the largest having six genotypes indicating genetic similarity among them. Character association indicated that among the seven agromorphological traits, five traits viz., days to flowering, days to maturity, head diameter, 100-seed weight and volume weight had significant and positive correlation with seed yield.

Interpretation : Based on PCA and cluster analysis, eight accessions GMU189, GMU799, GP 1217,

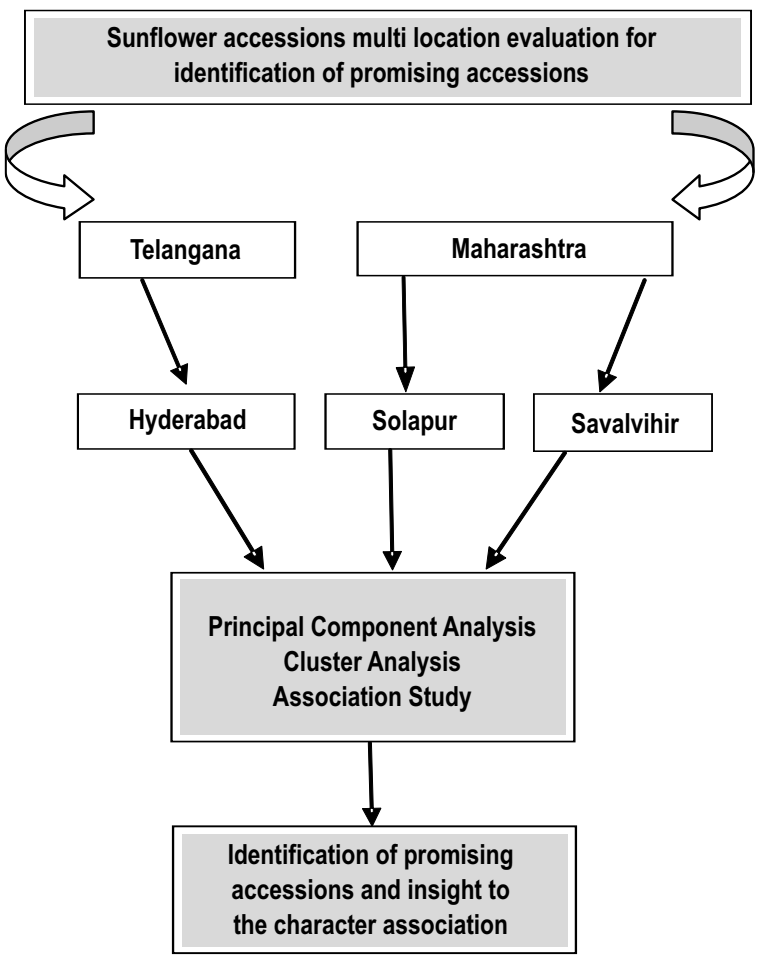
$\mathrm{GP}_{6} 271, \mathrm{GMU} 440, \mathrm{GP}_{6} 211$ $\mathrm{GP}_{6} 286$ and DRSF 113 were identified as high yielding which can be widely utilised for the development of new diverse varieties/ hybrids for enhanced seed yield under semi-arid conditions. 


\section{Introduction}

Sunflower is one of the important oilseed crops in India with productivity of $752 \mathrm{~kg} \mathrm{ha}^{-1}$ (GOI, 2016). Semi-arid regions are characterized by a climate with low or insufficient rainfall to sustain agricultural production. In India, almost 53.4 per cent land area comprises arid and semi-arid regions (GOI, 2004). The extent of genetic variability present in the germplasm for desired traits is the key for success of any crop improvement programmes aimed at development of new superior inbreds, varieties and hybrids (Dudhe et al., 2017). Bringing improvement over existing crop varieties and hybrids is a continuous process. To achieve this objective, the breeder has to identify diverse promising accessions from working germplasm.

Therefore, knowledge on the extent of diversity for the desired traits is essential for efficient germplasm conservation, characterisation and determining the relationships among germplasm accessions to enhance the efficiency of its management and genetic improvement (Geleta et al., 2005). Data generated through multilocation evaluation provides better indication about the buffering capacity and actual worth of the genotypes under diverse conditions. Multivariate statistical techniques like principal component analysis (PCA) and cluster analysis $(C A)$ which analyze multiple measurements based on morphological or molecular markers proved to be successful in selecting appropriate genotypes that meets the objectives of the breeding programme (Mohammadi and Prasanna, 2003). Cluster analysis is commonly used to study genetic diversity and for forming core subset for grouping accessions with similar characteristics into one homogenous category.

Clustering is also used to summarize information on relationships between objects by grouping similar units so that the relationships may be easily communicated. For analysing genetic diversity in sunflower, multivariate techniques are frequently employed (Muppidathi et al., 1995; Mohan and Seetharam, 2005; Kholghi et al., 2011 and Reddy et al., 2012). PCA is used to reveal patterns and eliminate redundancy in data sets (Adams, 1995) as morphological and physiological variations routinely occur in crop species. PCA technique is effective in finding the structure of the sets, grouping of genotypes and estimation of diversity of breeding materials. PCA has previously been used in sunflower either for grouping genotypes or for estimation of genetic diversity (Maruthi Sankar et al., 1999; Dong et al., 2007; Tabrizi et al., 2011). PCA is used to obtain a small number of linear combinations, which accounts for most of the variability in the evaluated germplasm. Hence, by considering the above aspects, this investigation was undertaken to study the variability of germplasm accessions by means of descriptive statistics, to understand the association of various characters, to identify high yielding accessions through PCA and cluster analysis by utilizing multilocation evaluation data generated by growing the germplasm under semi-arid environments of Telangana and Maharashtra states of India.

\section{Materials and Methods}

Experimental material and location : This study was conducted to characterize 32 sunflower accessions along with three checks viz., DRSF-113, Morden and Bhanu. Evaluation was carried out during kharif 2013 at three semi-arid locations which included one location in Telangana state (IIOR, Hyderabad) and two locations at Maharashtra (ZARS, Solapur; ARS, Savalvihir). The experimental design was a randomized complete block design (RCBD) with two replications. The accessions were planted at row to row plant spacing of $60 \times 30 \mathrm{~cm}$ on ridges and normal management practices were followed. Observations were recorded on five randomly selected plants per replication and included days to $50 \%$ flowering (FPF); days to maturity (DM), plant height in $\mathrm{cm}(\mathrm{PH})$, head diameter in $\mathrm{cm}(\mathrm{HD})$, seed yield per hectare in $\mathrm{kg}$ (YPH), 100-seed weight (SW) and volume weight (VW) in g. Seed yield per plant was converted to seed yield ha ${ }^{-1}$ by the formula:

Seed yield $h^{-1}=$ Seed yield per plant $x$ One hectare plant population.

Statistical analysis : The major descriptive statistics such as mean, range, standard deviation and coefficient of variation were computed using standard methods as described by Panse and Sukhatme (1964). Phenotypic correlation coefficients were calculated by the formula given by Johnson et al. (1955). Principal Component Analysis (PCA) was worked through correlation matrix. The Ward's method was used for clustering of genotypes into similarity groups. Cluster analysis and PCA were used to characterize germplasm and to group them based on their traits. $R$ version 3.1.3 package was used for determining the diversity and PCA analysis (R Core Team, 2013). Command 'hclust' command was used to draw denderogram. The biplot was generated by using the 'FactoMineR' (Factor analysis and data mining with $\mathrm{R}$ ) package (Husson et al., 2009) with commmand 'biplot'.

\section{Results and Discussion}

In any crop improvement programme, the main prerequisite for response to selection is the genetic variability in the population. The analysis of variance showed highly significant differences among the genotypes for all characters (Table 1). This indicated that germplasm under evaluation was genetically diverse and considerable amount of variability existed in the material, hence there is an opportunity for selection to develop new improved inbred lines. Earlier significant variation in sunflower inbreds was reported by Sujatha et al. (2002).

The wide range was exhibited for seed yield and the genotype $\mathrm{GP}_{2} 1217$ (1912 $\mathrm{kg} \mathrm{ha}^{-1}$ ) had the highest value while GP6714 (699 kg ha ${ }^{-1}$ ) recorded the lowest. The high yielding check, DRSF-113 recorded $1547 \mathrm{~kg} \mathrm{ha}^{-1}$. The genotypes GMU601 (87 days) recorded the minimum, while two genotypes GP6951 and GP61227 (103 days) recorded the maximum days to maturity (Table 2). The short duration check variety, Morden also 
Table 1 : Pooled ANOVA for seed yield and its component traits in sunflower

\begin{tabular}{llll}
\hline Traits & \multicolumn{3}{c}{ Mean sum of squares } \\
\cline { 2 - 4 } & $\begin{array}{l}\text { Replications } \\
\text { (d.f.=2) }\end{array}$ & $\begin{array}{l}\text { Treatments } \\
\text { (d.f.=31) }\end{array}$ & $\begin{array}{l}\text { Error } \\
\text { (d.f.=62) }\end{array}$ \\
\hline Seed yield & 140582.5 & $542002.8^{* *}$ & 8094.596 \\
50\% percent flowering & 101.5729 & $67.13441^{* *}$ & 14.66969 \\
Days to maturity & 21.125 & $68.12601^{* *}$ & 3.254032 \\
Plant height & 251.4254 & $1138.957^{* *}$ & 104.3114 \\
Head diameter & 0.605 & $16.38278^{*}$ & 0.388871 \\
100-Seed weight & 1.088189 & $2.695874^{* *}$ & 0.186122 \\
Volume weight & 5.917247 & $106.7118^{*}$ & 4.053228 \\
\hline
\end{tabular}

**and *significant at 0.01 and 0.05 level of significance. d.f. = Degrees of freedom recorded duration of 87 days. GP61227 recorded the maximum head diameter $(17.3 \mathrm{~cm})$ and 100-seed weight $(5.8 \mathrm{~g})$. Earlier Sudrik et al. (2014) reported similar results in sunflower.

The association of morphological traits was estimated by correlation analysis (Table 3). Character association indicated that among the seven agro-morphological traits, head diameter (0.82), 100-seed weight (0.8) and volume weight $(0.42)$ had significant and positive correlations with seed yield $(P=0.01$ level). Significant negative association of seed yield was observed with $50 \%$ flowering $(-0.33)$ and days for maturity $(-0.26)$. For the simultaneous improvement of traits in sunflower, Mogali and Virupakshappa (1994) studied the association of seed yield with yield related traits. Greater positive association observed for most of the characters with seed yield indicated that these

Table 2 : Mean of seed yield and its components of sunflower evaluated at 3 locations and 2 states

\begin{tabular}{|c|c|c|c|c|c|c|c|}
\hline Entry & YPH (kg ha-1) & FPF & DM & $\mathrm{PH}(\mathrm{cm})$ & $\mathrm{HD}(\mathrm{cm})$ & $\mathrm{SW}(\mathrm{g})$ & VW (g) \\
\hline GMU168 & 1419 & 56 & 89 & 147 & 14.2 & 4.4 & 41.3 \\
\hline GMU189 & 1863 & 65 & 97 & 145 & 16.4 & 5.0 & 40.6 \\
\hline GMU229 & 1445 & 59 & 90 & 102 & 14.8 & 4.5 & 38.4 \\
\hline GMU258 & 923 & 64 & 94 & 113 & 12.3 & 4.7 & 35.8 \\
\hline GMU440 & 1679 & 61 & 93 & 113 & 14.3 & 4.8 & 40.5 \\
\hline GMU601 & 1063 & 55 & 86 & 119 & 10.5 & 3.7 & 38.3 \\
\hline GMU616 & 1447 & 58 & 90 & 132 & 14.9 & 4.0 & 40.2 \\
\hline GMU713 & 1163 & 54 & 87 & 127 & 13.6 & 3.7 & 36.2 \\
\hline GMU776 & 1203 & 58 & 91 & 144 & 13.4 & 4.0 & 35.8 \\
\hline GMU753 & 1453 & 55 & 87 & 116 & 13.1 & 4.3 & 36.6 \\
\hline GMU786 & 1247 & 58 & 91 & 149 & 13.7 & 4.6 & 36.0 \\
\hline GMU787 & 1091 & 57 & 90 & 148 & 12.9 & 4.5 & 35.0 \\
\hline GMU799 & 1880 & 55 & 88 & 138 & 16.5 & 5.5 & 40.9 \\
\hline GMU798 & 1345 & 55 & 87 & 138 & 14.8 & 4.8 & 41.0 \\
\hline GMU834 & 1200 & 56 & 89 & 126 & 12.7 & 4.8 & 36.2 \\
\hline GMU889 & 1240 & 57 & 93 & 117 & 13.2 & 4.6 & 40.7 \\
\hline GMU897 & 1131 & 56 & 90 & 131 & 13.1 & 4.5 & 42.6 \\
\hline $\mathrm{GP}_{6} 211$ & 1678 & 67 & 99 & 156 & 14.8 & 5.7 & 39.3 \\
\hline $\mathrm{GP}_{6} 271$ & 1601 & 58 & 92 & 156 & 15.9 & 5.3 & 42.1 \\
\hline $\mathrm{GP}_{6} 286$ & 1750 & 60 & 95 & 147 & 16.4 & 5.0 & 35.0 \\
\hline $\mathrm{GP}_{6} 571$ & 1686 & 67 & 100 & 177 & 15.9 & 4.5 & 43.6 \\
\hline $\mathrm{GP}_{6} 644$ & 822 & 67 & 99 & 167 & 11.9 & 3.3 & 36.4 \\
\hline GMU797 & 1235 & 53 & 87 & 119 & 11.3 & 4.4 & 38.8 \\
\hline $\mathrm{GP}_{6} 951$ & 1116 & 70 & 103 & 165 & 11.6 & 4.2 & 37.3 \\
\hline $\mathrm{GP}_{2} 1217$ & 1912 & 53 & 87 & 126 & 17.2 & 5.7 & 35.9 \\
\hline $\mathrm{GP}_{6} 1227$ & 1006 & 70 & 103 & 174 & 12.1 & 3.6 & 36.4 \\
\hline $\mathrm{GP}_{6} 1475$ & 901 & 67 & 99 & 135 & 10.9 & 3.4 & 38.5 \\
\hline $\mathrm{GP}_{2} 1334-3$ & 967 & 69 & 99 & 127 & 14.1 & 3.0 & 32.9 \\
\hline $\mathrm{GP}_{6} 714$ & 699 & 69 & 99 & 163 & 10.3 & 2.9 & 37.6 \\
\hline DRSF-113 @ & 1547 & 58 & 90 & 155 & 13.6 & 5.2 & 41.8 \\
\hline Morden ( & 1233 & 52 & 87 & 117 & 12.5 & 4.9 & 37.2 \\
\hline Bhanu (C) & 1717 & 55 & 90 & 130 & 12.6 & 5.3 & 38.9 \\
\hline Mean & 1333 & 59.81 & 92.53 & 138.1 & 13.65 & 4.508 & 38.37 \\
\hline Min. & 699 & 52.00 & 86.00 & 102.0 & 10.33 & 2.990 & 32.85 \\
\hline Max. & 1912 & 70.00 & 103.00 & 177.0 & 17.23 & 5.790 & 43.55 \\
\hline SD & 323.18 & 5.61 & 5.09 & 19.15 & 1.79 & 0.72 & 2.57 \\
\hline CV (\%) & 24.24 & 9.39 & 5.50 & 13.87 & 13.13 & 16.06 & 6.71 \\
\hline S.E. $( \pm)$ & 57.13 & 0.99 & 0.90 & 3.39 & 0.32 & 0.13 & 0.46 \\
\hline
\end{tabular}

YPH : Yield per hectare, FPF : Days to 50 \% flowering; DM: Days to maturity; PH : Plant height; HD : Head diameter, SW : 100-seed weight and VW : Volume weight 
Table 3 : Phenotypic correlation coefficients for different traits in germplasms accessions from Telangana and Maharashtra

\begin{tabular}{lllllll}
\hline & FPF & DM & PH & HD & SW & VW \\
\hline YPH & $-0.33^{* *}$ & $-0.26^{* *}$ & -0.05 & $0.82^{* *}$ & $0.80^{* *}$ & $0.42^{* *}$ \\
FPF & & $0.96^{* *}$ & $0.56^{* *}$ & $-0.17^{* *}$ & $-0.44^{* *}$ & $-0.13^{* *}$ \\
DM & & & $0.63^{* *}$ & $-0.13^{* *}$ & $-0.36^{* *}$ & -0.09 \\
PH & & & & 0.03 & $-0.12^{* *}$ & $0.13^{* *}$ \\
HD & & & & & $0.61^{* *}$ & $0.27^{* *}$ \\
SW & & & & & & $0.36^{* *}$ \\
\hline
\end{tabular}

YPH : Seed yield per hectare; FPF : Days to $50 \%$ flowering; DM : Days to maturity; PH : Plant height; HD : Head diameter; SW : 100-seed weight and VW: Volume weight

characters could be simultaneously improved and further recommend that increase in any one would lead to improvement of other characters.

Correlation with $50 \%$ flowering was significantly negative for head diameter $(-0.17), 100$-seed weight $(-0.44)$ and volume weight $(-0.13)$. Lack of strong association between these characters indicates that selection made for early types will not influence these characters. Perusal on correlation among component characters revealed that strong associations among desirable component characters exist particularly for head diameter, 100-seed weight and volume weight for the improvement of seed yield in sunflower. Hence, selection criteria based on these component traits along with seed yield will be more useful than based solely on seed yield. Simultaneously, improvement in seed yield along with other component traits in sunflower is important as reported earlier (Kaya et al., 2009; Anandhan et al., 2010).

The principal component analysis has practical application in selection of superior genotypes for breeding (Tabrizi et al., 2011). The results of PCA revealed that the first four components with eigen value of greater than 0.43 contributed about $93.3 \%$ of total variability in 32 genotypes involving all the seven traits (Table 4). The importance of traits towards the principal components could be seen from the corresponding eigen values which are presented in Table 4 . Eigen values are the variance explained by each PC and to repeat, are constrained to decrease monotonically from the first $P C$ to the last. In this case it decreased from 3.27 (PC 1) to 0.02 (last PC). The eigen values plotted on a screen plot show a decreasing trend which explains the variance by additional principal components (Legendre and Legendre, 1998). The eigen values and the variance associated with each principal component decreased gradually. The first principal component accounted for $46.7 \%$ of the total variation in the material studied. Hussain et al. (2017) on evaluation of sunflower hybrids assessed for yield related traits, the first two principal components contributed $73.7 \%$ variability among the hybrids while the remaining $26.3 \%$ variability was due to other components. Among the traits, seed yield (0.45) contributed maximum to the variation and divergence followed by head diameter, 100-seed weight, volume weight indicating the importance of these components as selection indices. Hussain et al. (2017) also reported greatest variation due to seed yield in PC 1 which is in agreement with the present study. Three characters viz., $50 \%$ flowering $(-0.42)$, days to maturity $(-0.403)$ and plant height $(-0.23)$ showed negative contribution to PC 1 indicating that genotypes with negative values of PC 1 had reduced height, early flowering and maturity.

The PC 2 contributed $28.78 \%$ of the total variation and the characters whose contribution was negative in PC 2 showed negative associations among the traits. The PC 3 accounted for $11.56 \%$ of the total variation in the accessions studied. Among the traits that accounted for this variation head diameter contributed the highest (0.39) followed by seed yield $(0.17)$ and days to maturity with minimal variation. The fourth principal component (PC 4) contributed $6.2 \%$ of the total variation. The characters that contributed to this variation include head diameter $(0.58)$, seed yield (0.79), 100-seed weight (0.44) and days to maturity (0.28). The observations are in agreement with those of Tabrizi et al., (2011) who evaluated the contribution of each trait to the total variation while evaluating sunflower hybrids at germination and early seedling growth stage.

APC biplot (Fig. 1) showed that variables and genotypes are super imposed on the plot as vectors. The biplot showed that head diameter, 100-seed weight, volume weight and seed yield, as a whole contributed maximum towards the variability in the germplasm. For example, the accessions $\mathrm{GP}_{6}$ 1217, 286, 271, 211, GMU799, 440, 189 and DRSF113 were scattered around the vectors of head diameter, 100-seed weight, volume weight and seed yield. Likewsie, $\mathrm{GP}_{6} 1227$ and $\mathrm{GP}_{6} 951$ were scattered around the vectors for $50 \%$ flowering and days to maturity. This is explained through the mean values of these genotypes for seed yield and days to maturity (Table 2). Hence, genotypes $\mathrm{GP}_{6} 1217$, 286, 271, 211, GMU799, 440, 189 and DRSF113 can be

Table 4 : Principal components showing the eigen values and proportion of variation

\begin{tabular}{lllllll}
\hline & \multicolumn{5}{c}{ Principal component axis } \\
\cline { 2 - 6 } & 1 & $\mathbf{2}$ & $\mathbf{3}$ & $\mathbf{4}$ & $\mathbf{5}$ & $\mathbf{6}$ \\
\hline Eigen values & 3.27 & 2.01 & 0.80 & 0.43 & 0.33 & 0.10 \\
Proportion of Variance (\%) & 46.731 & 28.787 & 11.568 & 6.268 & 0.047 & 0.017 \\
Cumulative Variation (\%) & 46.73 & 75.51 & 87.08 & 93.34 & 98.11 & 99.65 \\
\hline
\end{tabular}




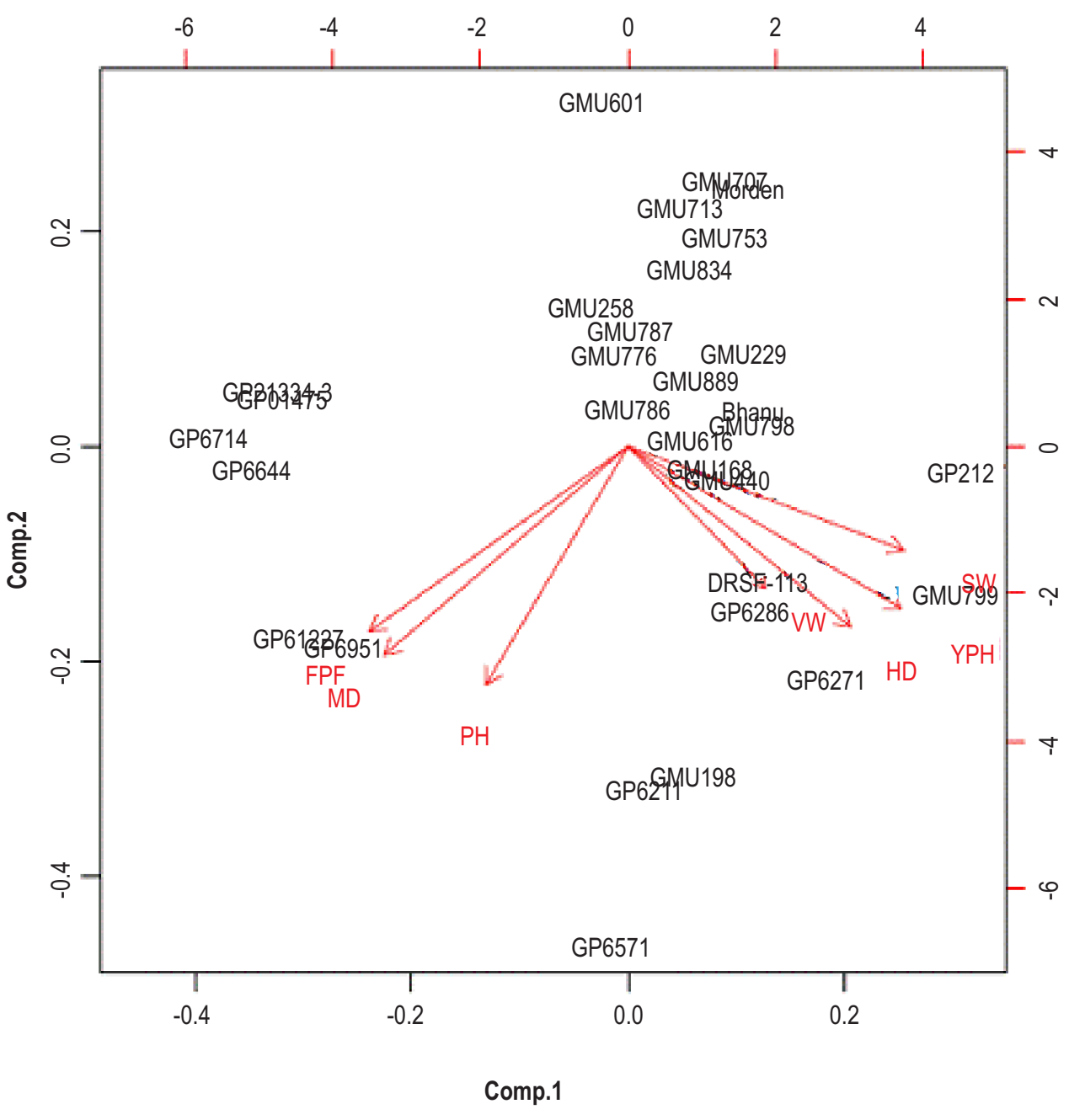

Fig. 1 : Biplot between PCs 1 and 2 showing contribution of various traits. YPH : Seed yield per hectare, FPF : Days to $50 \%$ flowering; DM : Days to maturity; PH: Plant height; HD : Head diameter, SW: 100-seed weight and VW: Volume weight.

considered as high yielding and $\mathrm{GP}_{6} 1227$ and $\mathrm{GP}_{6} 951$ can be regarded as long duration genotypes under semi-arid environments. For semi-arid environments, sunflower growing farmers prefer medium duration genotypes. Hence, selection for any of these traits should be accompanied by the associated traits, as it provides an opportunity to exert multi-trait selections in sunflower breeding as indicated by Ghaffari et al. (2011). Kroonenberg (1995) concluded that the angle of vectors shows correlations among the traits. In Fig. 1, there were some vectors for different traits, viz., head diameter, 100-seed weight, volume weight and seed yield which had a small angle with each other indicating the existence of positive associations among these traits. Likewise, plant height, days to $50 \%$ flowering, days to maturity showed positive correlations which are in agreement with the studies of Tabrizi et al. (2011) who recorded similar type of observations based on angle of vectors while evaluating sunflower hybrids during germination and early seedling growth.

In the present study, the objective was to identify high yielding accessions through cluster analysis regardless of the trait expression. In this investigation, 32 genotypes were grown across three test sites and subjected to hierarchical clustering (HCA) and the dendrogram is presented (Fig. 2). The 32 genotypes were grouped into 11 clusters, out of which cluster IX was the largest having 6 genotypes indicating genetic similarity among them (Table 6, Fig. 2). Cluster VII is a solitary cluster containing only one genotype indicating the uniqueness of the genotype when compared to other genotypes. The GP lines used in this study were derived from systematic breeding for several generations for high yield under different genetic backgrounds. The same trend of pattern i.e. grouping of the germplasm and 
Table 5 : Principal component analysis for sunflower accessions - non rotated loadings

\begin{tabular}{lllll}
\hline Character & PC1 & PC2 & PC3 & PC4 \\
\hline YPH & 0.451 & -0.342 & 0.178 & 0.798 \\
FPF & -0.428 & -0.391 & 0.135 & 0.381 \\
DM & -0.403 & -0.441 & 0.127 & 0.289 \\
PH & -0.235 & -0.503 & -0.159 & -0.808 \\
HD & 0.368 & -0.381 & 0.390 & 0.586 \\
SW & 0.456 & -0.219 & -0.116 & -0.762 \\
VW & 0.228 & -0.300 & -0.864 & 0.298 \\
\hline
\end{tabular}

YPH : Seed yield per hectare; FPF: Days to $50 \%$ flowering; DM : Days to maturity; PH : Plant height; HD : Head diameter; SW : 100-seed weight and VW: Volume weight

Table 6 : Constituents of 11 clusters of 32 sunflower accessions

\begin{tabular}{lll}
\hline Cluster & $\begin{array}{l}\text { No. } \\
\text { accessions }\end{array}$ & Accessions \\
\hline Cluster I & 3 & GMU189, GMU799, GP21217 \\
Cluster II & 2 & GP6271, DRSF-113 C \\
Cluster III & 5 & GMU440, GP6211, GP6286, \\
& & GP6571, Bhanu@ \\
Cluster IV & 2 & GMU258, GP61475 \\
Cluster V & 2 & GP61227, GP21334-3 \\
Cluster VI & 2 & GP6644, GP6714 \\
Cluster VII & 1 & GMU798 \\
Cluster VIII & 4 & GMU168, GMU229, GMU616, GMU753 \\
Cluster IX & 6 & GMU776, GMU786, GMU834, GMU889, \\
& & GMU797, Morden@ \\
Cluster X & 2 & GMU713, GMU897 \\
Cluster XI & 3 & GMU601,GMU787,GP6951 \\
\hline
\end{tabular}

Table 7 : Cluster means of 11 clusters of 32 sunflower accessions from Telangana and Maharashtra

\begin{tabular}{llllllll}
\hline & YPH & FPF & DM & PH & HD & SW & VW \\
\hline Cluster I & 1441.0 & 57.0 & 89.0 & 124.2 & 14.3 & 4.3 & 39.1 \\
Cluster II & 1188.6 & 56.0 & 89.0 & 132.3 & 13.3 & 4.2 & 36.0 \\
Cluster III & 1702.0 & 62.0 & 95.4 & 144.6 & 14.8 & 5.0 & 39.4 \\
Cluster IV & 1345.0 & 55.0 & 87.0 & 138.0 & 14.8 & 4.8 & 41.0 \\
Cluster V & 1100.2 & 59.5 & 92.2 & 140.7 & 12.0 & 4.2 & 38.3 \\
Cluster VI & 1574.0 & 58.0 & 91.0 & 155.5 & 14.8 & 5.2 & 41.9 \\
Cluster VII & 1885.0 & 57.6 & 90.6 & 136.3 & 16.7 & 5.4 & 39.1 \\
Cluster VIII & 949.2 & 67.5 & 98.7 & 137.2 & 12.4 & 3.7 & 35.8 \\
Cluster IX & 1238.7 & 55.0 & 89.5 & 125.5 & 12.7 & 4.6 & 38.1 \\
Cluster X & 699.0 & 69.0 & 99.0 & 163.0 & 10.3 & 2.9 & 37.6 \\
Cluster XI & 822.0 & 67.0 & 99.0 & 167.0 & 11.9 & 3.3 & 36.4 \\
\hline
\end{tabular}

YPH: Seed yield per hectare; FPF : Days to $50 \%$ flowering; DM : Days to maturity; PH: Plant height; HD : Head diameter; SW: 100-seed weight and VW: Volume weight

gene pool lines in different clusters can be seen in Fig. 2 viz. clusters V and VI comprised of GP lines whereas clusters VIII, IX and $X$ comprised of GMU accessions. Hence, the genotypes within the same clusters may have originated from similar genetic

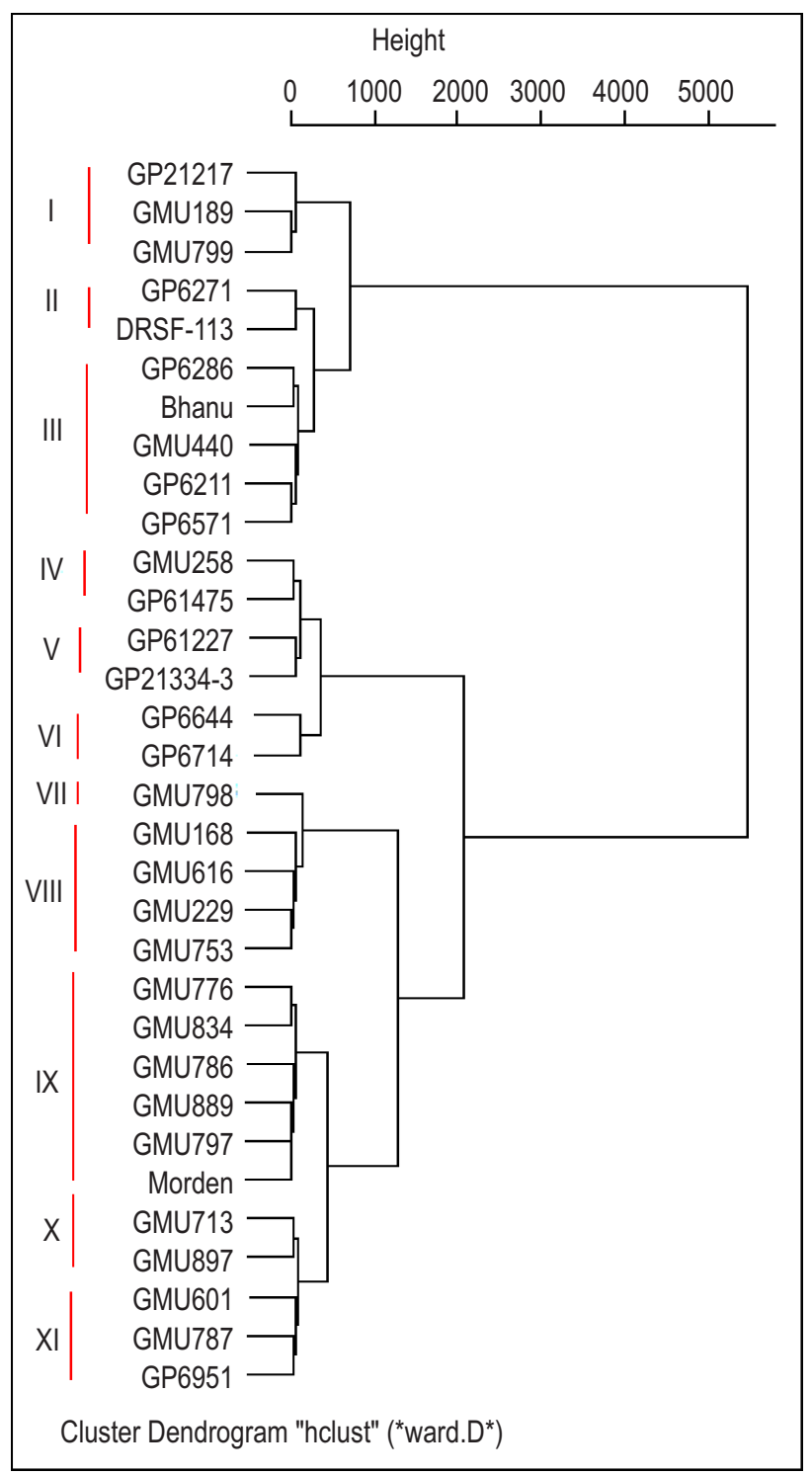

Fig. 2 : Dendrogram for 32 sunflower accessions produced by Ward's clusters analysis (scale: Squared Euclidean distance).

backgrounds. Reddy et al. (2012) grouped 64 sunflower accessions into nine clusters and observed that genotypes of different origin were clustered together, indicating absence of relationship between genetic and geographic diversity. Clusters II, I and III comprised of 2, 3 and 5 genotypes, respectively and based on their mean performance these genotypes were found to be high yielding with seed yield in the range of $1500-1900 \mathrm{~kg} \mathrm{ha}^{-1}$. Hence, these clusters can be considered as germplasm accessions with high seed yield potential and could be exploited in breeding programme. All the other germplasm accessions are moderate yielders and were grouped under IV to XI clusters. Srinivas et al. (2006) identified the high yielding breeding material based on cluster analysis which confirms the present study.

As shown in Table 7, the cluster VII recorded highest 
mean values for seed yield (1885 $\mathrm{kg} \mathrm{ha}^{-1}$ ) whereas cluster $X$ recorded the lowest cluster mean for 100-seed weight. The genotypes with lowest seed yield are included in cluster $X$ as indicated by lowest cluster mean value of $699 \mathrm{~kg} \mathrm{ha}^{-1}$. Clusters $X$ and $\mathrm{XI}$ exhibited highest cluster mean values for days to maturity (99.0) indicating the inclusion of late maturing accessions in that cluster. Genotypes in cluster VI recorded highest volume weight $(41.9 \mathrm{~g})$ while the least was recorded by cluster VIII $(35.8 \mathrm{~g})$. Earlier, sunflower genetic divergence among parental lines, inbreds and working germplasm was studied to group the germplasm accessions based on cluster means of yield and yield related traits (Ananda Kumar et al., 2007; Reddy et al., 2012). Based on the diversity recorded in seed yield and yield related traits, Reddy et al. (2012) emphasized the use of diverse parents in crossing programme for combining desirable genes and for obtaining novel and greater recombination.

It is concluded that substantial amount of variability is present among the accessions. The study led to identification of promising accessions across the diverse environmental conditions through multi-location evaluation. Eight promising accessions identified for high seed yield could be utilised for the development of high yielding genotypes as well as inbred lines for enhanced seed yield under semi-arid conditions.

\section{Acknowledgments}

We thank the editor and two anonymous reviewers for their constructive comments, which helped us to improve the manuscript.

\section{References}

Adams, M.W.: An estimate of homogeneity in crop plants with special reference to genetic vulnerability in dry season. Phseolus vulgaris. Ephytica, 26, 665-679(1995).

Ananda Kumar, B.V., M. Parameshwarappaand B.S. Linga Raju: Genetic divergence in parental and inbred lines of sunflower (Helianthus annuus L.). Karnataka J. Agric. Sci., 21, 339-342 (2007).

Anandhan, T., P. Manivannan, P. Vindhiyavarman and P. Jeyakumar Correlation for oil yield in sunflower (Helianthus annuus L.). Electronic J. Plant Breed., 1, 869-871 (2010).

Dong, G.J., G.S. Liu and K.F. Li : Studying genetic diversity in the core germplasm of confectionary sunflower (Helianthus annuus L.) in China based on AFLP and morphological analysis. Russian J. Genet., 43, 627-635 (2007).

Dudhe, M.Y., A.B. Rajguru, K.D. Bhoite and P. Madhuri : Genetic evaluation and identification of stable sunflower genotypes under semi-arid dryland conditions of Telangana and Maharashtra states. SABRAO J. Breed. Genet., 49, 83-93 (2017).

Geleta, L. F., M. T. Labuschagne and C. D. Viljoen : Genetic variability in pepper (Capsicum annuum L.) estimated by morphological data and amplified fragment length polymorphism markers. Biodivers. Conserv., 14, 2361-2375(2005)

Ghaffari, M., I. Farrokhib and M. Mirzapour : Combining ability and gene action for agronomic traits and oil content in sunflower (Helianthus annuus L.) using $F_{1}$ hybrids . J. Crop Breed., 1, 73-84 (2011).
GOI: Agricultural statistics at a glance. Directorate of Economics and Statistics, Ministry of Agriculture, Government of India (2016).

GOI: India first National Communication to UNFCCC. MoEF, Government of India (2004)

Hussain, F., M. Rafiq, M. Ghias, R. Qamar, M.K. Razzaq, A. Hameed, S. Habib and H.S.B. Mustafa : Genetic diversity for seed yield and its components using principal component and cluster analysis in sunflower (Helianthus annuus L.). Life Sci. J., 14, 71-78 (2017).

Husson, F., J. Josse, L`e S and J. Mazet : FactoMineR: Multivariate exploratory data analysis and data mining with $R$. R package version 1.12, URL http://factominer.free.fr (2009).

Jonson, H.W., H.F. Robinson and R.E. Comstock : Estimates of genetic and environmental variability in soybean. Agron. J., 47, 314-18 (1955).

Kaya, Y., G. Evci, S. Durak, V. Pekcan and T. Gucer : Yield components affecting seed yield and their relationship in sunflower (Helianthus annuus L.). Pakistan J. Bot., 41, 2261-2269 (2009).

Kholghi, M., I. Bernousi, R. Darvishzadeh, A. Pirzad and H. Hatami Maleki: Collection, evaluation and classification of Iranian confectionary sunflower (Helianthus annuus L.) populations using multivaraite statistical techniques. African J. Biotechnol., 10, 5444-5451 (2011).

Kroonenberg, P.M.: Introduction to biplots for $\mathrm{G} \times \mathrm{E}$ tables. Department of Mathematics. Res. Report 51. University of Queensland, Australia (1995).

Legendre, P. and L. Legendre : Numerical Ecology. Elsevier:Amsterdam p. 853 (1998).

Maruthi Sankar, G.R., D. Narasimha Murthy, M. Vanaja and P. Raghuram Reddy: A multiple selection index for selecting sunflower genotypes using principal component analysis. Indian J. Dryland Agril. Res. Develop., 14, 93-103 (1999).

Mogali, S.C. and K. Virupakshappa: Inter character association and path coefficient analysis in sunflower (Helianthus annuus L.). Indian J. Genet. Pl. Breed., 54, 366-370 (1994).

Mohammadi, S.A. and B.M. Prasanna : Analysis of genetic diversity in crop plants - salient statistical tools and considerations. Crop Sci., 43, 1235-1248 (2003).

Mohan, G. S. and A. Seetharam : Genetic divergence in lines of sunflower derived from inter specific hybridization. SABRAO J. Breed. Genet., 37, 77-84 (2005).

Muppidathi, N., R. Sankarapandian and S. Rajarathinam : Genetic divergence, correlation and path analysis in sunflower (Helianthus annuus L.). Crop Imp., 22, 221-224 (1995).

Panse, V.G. and P.V. Sukhatme : Statistical Methods for Agricultural Workers. $2^{\text {nd }}$ Edn., ICAR, New Delhi (1964).

R Core Team.: R : A language and environment for statistical computing [Software]. Available from http://www.r-project.org/ (2013)

Reddy, S.M., T.D. Reddy and M.Y. Dudhe : Analysis of genetic diversity in germplasm accessions of sunflower (Helianthus annuus L.) MadrasAgric. J., 99, 457-460 (2012).

Srinivas, B., K.S. Dangi, L. Prayaga and S. Sudheer Kumar : Genetic divergence studies in sunflower (Helianthus annuus L). germplasm lines. J. Oilseeds Res., 23, 49-51(2006).

Sudrik, B. P., M. K. Ghodke, V. S. Patil, S. K. Chavan and N. B. Kesale Evaluation and characterisation of sunflower (Helianthus annuus L.) germplasm. J. Crop Weed., 10, 73-76 (2014).

Sujatha, H.L. Chikkadevaiah and R. Nandini : Genetic variability study in sunflower inbreds. HELIA., 25, 93-100 (2002).

Tabrizi, H. Z., E. Sahin and K. Haliloglu : Principal components analysis of some sunflower hybrids at germination and early seedling growth stage. J. Faculty Agri. Atatürk Univ., 42, 103-109 (2011). 